\title{
Transplante de valva mitral heteróloga. Nova alternativa cirúrgica: estudo clínico inicial
}

\author{
Mário O. VRANDECIC*, Bayard GONTIJO FILHO*, Fernando Antônio FANTINI*, João Alfredo de \\ PAULA E SILVA, Juscelino Teixeira BARBOSA*, Cristiana GUTIERREZ* ${ }^{*}$ Maurício R. BARBOSA*, \\ Sérgio Almeida de OLIVEIRA ${ }^{\star \star}$, Mário MOREA M** $^{\star \star \star}$
}

RBCCV 44205-202

VRANDECIC, M. O.; GONTIJO FILHO, B.; FANTINI, F. A.; PAULA E SILVA, J. A.; BARBOSA, J. T.; GUTIERREZ, C.; BARBOSA, M. R.; OLIVEIRA, S. A.; MOREA, M. - Tranplante heterólogo de valva mitral. Nova alternativa cirúrgica: estudo clínico inicial. Rev. Bras. Cir. Cardiovasc., 8(2):83-90, 1993.

RESUMO: A substituição da valva mitral tem sido realizada, nestes 30 anos, usando-se o modelo aórtico. Embora o resultado clínico, na maioria dos pacientes seja satisfatório, existem, restriçōes específicas, tanto entre as biopróteses, como nas próteses mecânicas. A experiência no tratamento dos tecidos biológicos, assim como a fabricação de substitutos valvares, há 2 décadas, tem permitido o desenvolvimento da valva mitral heteróloga. Este substituto mitral foi implantado em 38 pacientes, com a preservação da função ventricular. A idade média foi de 29 anos, predominando o sexo feminino $(69 \%)$, e a etiologia reumática em $86 \%$. A dupla lesão foi a mais freqũente (53\%). A classificação funcional deste grupo engloba $(47 \%)$ em classe II e $(53 \%)$ em classe IV da NYHA. A técnica cirúrgica é reproduzível e proporcionou resultados clínicos satisfatórios durante 12 meses de evolução, demonstrando que a valva mitral heteróloga é o substituto natural, quando indicada a troca valvar. Houve uma reoperação em paciente que apresentou insuficiência mitral moderada, devido à desproporção entre a valva escolhida e o anel mitral bastante dilatado. Os resultados clínico, hematológico e ecocardiográfico têm sido extremamente gratificantes, durante o período de seguimento. O desenho mitral natural, aliado ao tratamento anticalcificante, é o que deve proporcionar melhor qualidade de vida e a durabilidade desejada.

DESCRITORES: valva mitral, cirurgia; valvas cardiacas, cirurgia.

\section{INTRODUÇÃO}

O objetivo fundamental do tratamento cirúrgico das doenças valvares cardíacas é proporcionar melhor qualidade de vida, aliada a uma sobrevida adequada.

Neste sentido, o capítulo da cirurgia da valva mitral é fascinante, não só do ponto de vista histórico, mas, principalmente, pelas conquistas substanciais conseguidas dentro da cardiologia clínica, determinando com precisão o perfil específico da disfunção da valva mitral, assim como o melhor conhecimento da anatomia do complexo mitral e os avanços da cirurgia cardíaca.

Entre os pioneiros da abordagem cirúrgica das lesões de valva mitral, BRUNTON ${ }^{3}$, em 1902, já abordava o tratamento da estenose mitral. TUFFIER 19, SOUTTAR ${ }^{18}$, BAILEY \& BOLTON ${ }^{2}$, GLOVER \& DAVILA ${ }^{11}$, ROSS ${ }^{16}$, DURAN \& UBAGE ${ }^{10}$, CARPENTIER et alii ${ }^{6}$ e tantos outros contribuíram para

Trabalho realizado no Instituto Biocór. Belo Horizonte, MG, Brasil.

Apresentado ao $20^{\circ}$ Congresso Nacional de Cirurgia Cardíaca. Maceió, AL, 2 e 3 de abril, 1993.

Laureado com o "Prêmio Nacional de Cirurgia Cardiaca - 1993".

- Do Instituto Biocór.

* Do Hospital da Beneficência Portuguesa. São Paulo, SP

*.. Da Universidade de Torino. Itália.

Endereço para separatas: Mário Vrandecic. Caixa Postal 106. 30161-970 Belo Horizonte, MG, Brasil. 
VRANDECIC, M. O.; GONTIJO FILHO, B.; FANTINI, F. A.; PAULA E SILVA, J. A.; BARBOSA, J. T.; GUTIERREZ, C.; BARBOSA, M. R.; OLIVEIRA, S. A.; MOREA, M. - Tranplante heterólogo de valva mitral. Nova alternativa cirúrgica: estudo clínico inicial. Rev. Bras. Cir. Cardiovasc., 8(2):83-90, 1993.

o presente estágio alcançado na cirurgia da valva mitral.

Os substitutos valvares em uso clínico há mais de 30 anos têm proporcionado resultados adequados, embora existam restrições específicas de durabilidade entre as biopróteses e do uso de anticoagulantes entre as próteses mecânicas.

A falta do substituto ideal para a valva mitral tem determinado o aprimoramento de técnicas cirúrgicas que visam à sua conservação sendo, atualmente, a plástica, sem dúvida, a cirurgia mais indicada.

O estágio avançado da doença nem sempre permite a conservação da valva mitral, tornando-se necessária a sua substituição.

Estudos comparativos entre a troca mitral e a sua plástica demonstram melhores resultados para a última $4,5,14,15$. DAVID 7 e DAVID et alii 8,9 ressaltam a importância do aparelho subvalvar na preservação da função do ventrículo esquerdo e, portanto, enfatizam a sua preservação parcial, mesmo durante a troca da valva mitral.

A alternativa hoje existente é o uso da valva mitral heteróloga de desenho específico, para atender as necessidades da idiosincrasia de fluxo e contratilidade própria do ventrículo esquerdo, motivo do presente estudo clínico ${ }^{20}$.

\section{MATERIAL E MÉTODO}

\section{Valva Mitral Heteróloga}

A pesquisa da valva mitral heteróloga foi realizada no Instituto Biocór e é fabricada pelos Laboratórios Biocór Indústria e Pesquisas Ltda., em Nova Lima, Minas Gerais. É obtida imediatamente após o abate de suínos, por pessoal especializado, usando-se técnica cirúrgica específica, de modo a preservar a integridade do material heterólogo.

A esterilização - preservação do complexo valvar mitral é feita sem uso de pressão e dentro das normas de controle de qualidade, durante cada etapa de fabricação. É estabilizada com glutaraldeído ${ }^{23}$, sendo que é o modelo NO-REACT por processo anticalcificante sem o uso de glutaraldeído. Após a estabilização do tecido (Tanning) é preparada de modo a atender as necessidades para seu implante.

O anel mitral é reforçado usando-se um delicado colar de pericárdio bovino, previamente tratado, e as cordas tendíneas afixadas entre 2 enxertos de pericárdio bovino, respeitando-se a origem espacial.
O formato do pericárdio, que é a nova origem das cordas, possui bordas necessárias para sua fixação em cada músculo papilar (Figura 1).

A valva é apresentada nos diâmetros entre 11 $\mathrm{mm}$ a $3 \mathrm{~mm}$.

A experimentação animal aguda, em suínos, foi fundamental para o estabelecimento de protocolo que permitisse a escolha do tamanho adequado para cada paciente.

Em essência, este estudo demonstrou que a medida da valva deve ser sempre feita ao nível da via de saída do ventrículo esquerdo, isto é, o espaço compreendido entre os trígonos fibrosos, devidamente marcado com a letra $x$ no anel de sutura da valva.

E fundamental que estas medidas sejam idênticas, para o bom funcionamento da valva.

Com relação ao novo tratamento anticalcificante, tanto a experimentação animal, laboratorial e in vitro, quanto aos testes de fadiga, demonstraram excelente desempenho, durabilidade, resistência, ausência de calcificação e, principalmente, falta de reação do tipo "corpo estranho", comum ao tratamento com glutaraldeído.

\section{Protocolo de Implante}

A técnica cirúrgica deve incluir as seguintes considerações:

1) Análise detalhada do complexo valvar mitral.

2) Seleção adequada do tamanho da valva mitral heteróloga;

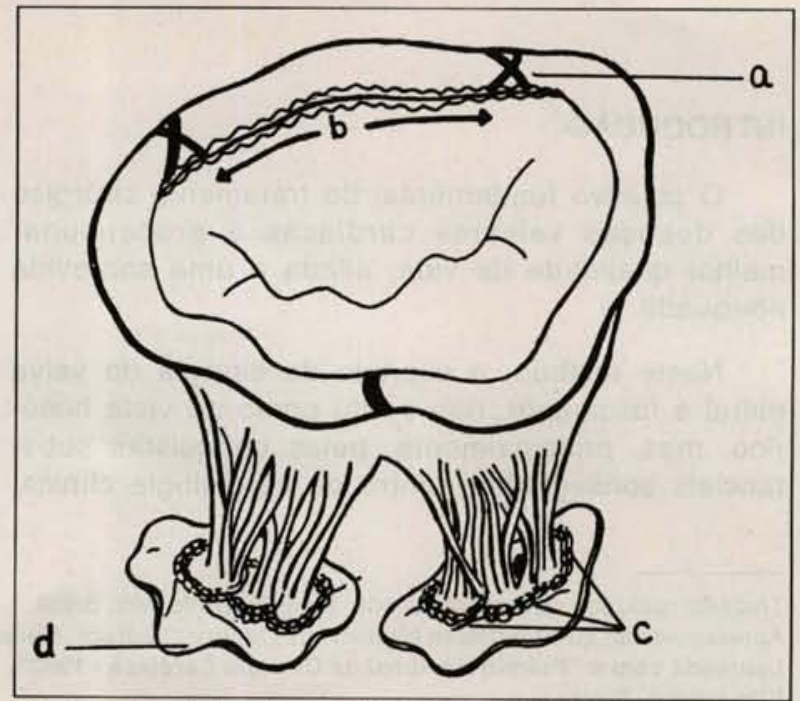

Fig. 1 - a) anel de sutura recoberto por pericárdio; b) cúspide anterior; c) nova origem das cordas tendineas; d) enxerto de pericárdio usado na fixaçăo do músculo papilar. 
VRANDECIC, M. O.; GONTIJO FILHO, B.; FANTINI, F. A.; PAULA E SILVA, J. A.; BARBOSA, J. T.; GUTIERREZ, C.; BARBOSA, M. R.; OLIVEIRA, S. A.; MOREA, M. - Tranplante heterólogo de valva mitral. Nova alternativa cirúrgica: estudo clínico inicial. Rev. Bras. Cir. Cardiovasc., 8(2):83-90, 1993.

3) Planejamento específico da distribuição e número de pontos de sutura em cada músculo papilar.

4) Determinação do tamanho correto da valva mitral heteróloga com relação à altura do aparelho subvalvar e espaço intertrigonal. Esta aferição deverá ser feita in situ, não apenas para assegurar o tamanho correto da valva, como também para determinar o melhor ângulo das suturas em cada músculo papilar. É aconselhado o uso de fio de monofilamento agulhado 4-0 e agulha de $2,5 \mathrm{~cm}$ de comprimento, o que facilita a colocação das suturas no músculo papilar. Tem sido a nossa rotina o uso de fios contendo "pledgets" de $3 \mathrm{~mm}$.

5) A fixação do anel de sutura da valva mitral heteróloga ao anel mitral do paciente é feita usando-se sutura contínua de monofilamento 4-0 e agulha de $2,5 \mathrm{~cm}$. Essa sutura é iniciada a nível dos reparos previamente inseridos nos ângulos que delimitam a via de saída do ventrículo esquerdo e a porção média da semicircunferência da cúspide posterior.

6) As manobras intra-operatórias para a determinação da suficiência mitral são, em geral, pouco precisas; assim, o uso de ecodoppler peroperatório via transesofágica ou epicárdica determina a qualidade do resultado de modo inequívoco. Portanto, a análise per-operatótia é fundamental.

\section{Técnica Cirúrgica}

A via de acesso é a esternotomia mediana, com uso de circulação extracorpórea e oxigenador de bolhas. A proteção miocárdica é feita com o uso da solução de St. Thomas e a exposição da valva mitral via atriotomia esquerda convencional. A temperatura esofágica é mantida em torno de $28^{\circ} \mathrm{C}$. E fundamental que a seqüência descrita acima seja rigorosamente seguida, lembrando-se que o sucesso cirúrgico depende exclusivamente da escolha correta do substituto valvar.

Após a análise do aparelho valvar mitral, é usado - medidor Biocór antes da excisão da valva, de modo que as ranhuras de 2 postes do medidor coincidam com a via de saída do VE, determinandose o tamanho da valva mitral heteróloga.

A retirada da valva mitral é feita de modo a conservar a origem das cordas tendíneas, preservando os músculos papilares. A seguir, são colocados pontos de reparo em cada pilar da via de saída do VE, assim como na porção média da semicircunferência do anel da cúspide posterior; a valva é inserida no do VE, de modo a comprovar que a altura do aparelho subvalvar e a distância intertrigonal sejam adequadas.

A colocação dos pontos em "pledget" nos músculos papilares é em número suficiente para que a nova origem das cordas seja assentada no topo de cada músculo papilar, mantendo-se a tensão do enxerto de pericárdio e respeitando a distribuição homogênea das mesmas.

Em geral, são necessários de 4 a 8 pontos em "U" em cada músculo papilar; é conveniente que os pontos sejam ancorados na base de cada músculo, em primeiro lugar na região anterior ou superior e depois na região posterior ou inferior; os pontos são ancorados na borda livre do enxerto de pericárdio, que é a nova origem das cordas tendíneas.

Durante esse procedimento, é fundamental que o alinhamento entre os pilares da via de saída do $V E$ e a marca de cada trígono da valva mitral heteróloga $(X)$ esteja sempre coincidente. É também importante o cuidado de evitar rotações do aparelho subvalvar.

A exposição dos músculos papilares determinará quais os pontos a serem aproximados de início. Novamente, é verificada a atual posição das cordas e a orientação intertrigonal correspondente.

A sutura contínua do anel mitral é iniciada em cada ponto de reparo prévio, o que facilita a sua boa distribuição. Não é freqüente a redundância do perímetro do anel mitral, principalmente nos pacientes com insuficiência mitral, o que exige, às vezes, maior número de pontos de reparo (Figuras 2, 3 e 4).

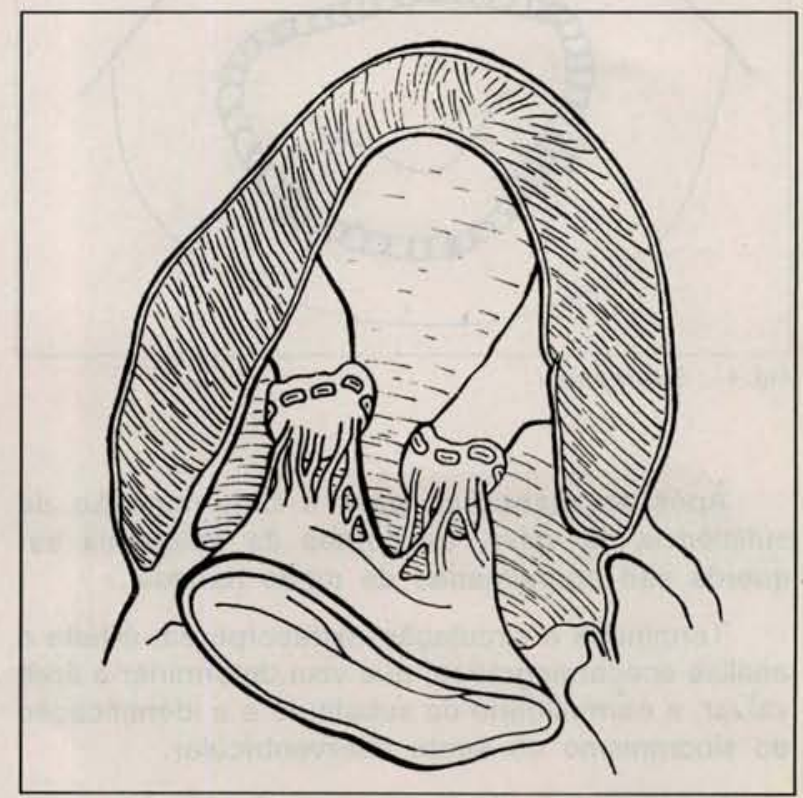

Fig. 2 - Fixação da valva mitral heteróloga aos músculos papilares. 
VRANDECIC, M. O.; GONTIJO FILHO, B.; FANTINI, F. A.; PAULA E SILVA, J. A.; BARBOSA, J. T.; GUTIERREZ, C.; BARBOSA, M. R.; OLIVEIRA, S. A.; MOREA, M. - Tranplante heterólogo de valva mitral. Nova alternativa cirúrgica: estudo clínico inicial. Rev. Bras. Cir. Cardiovasc., 8(2):83-90, 1993.

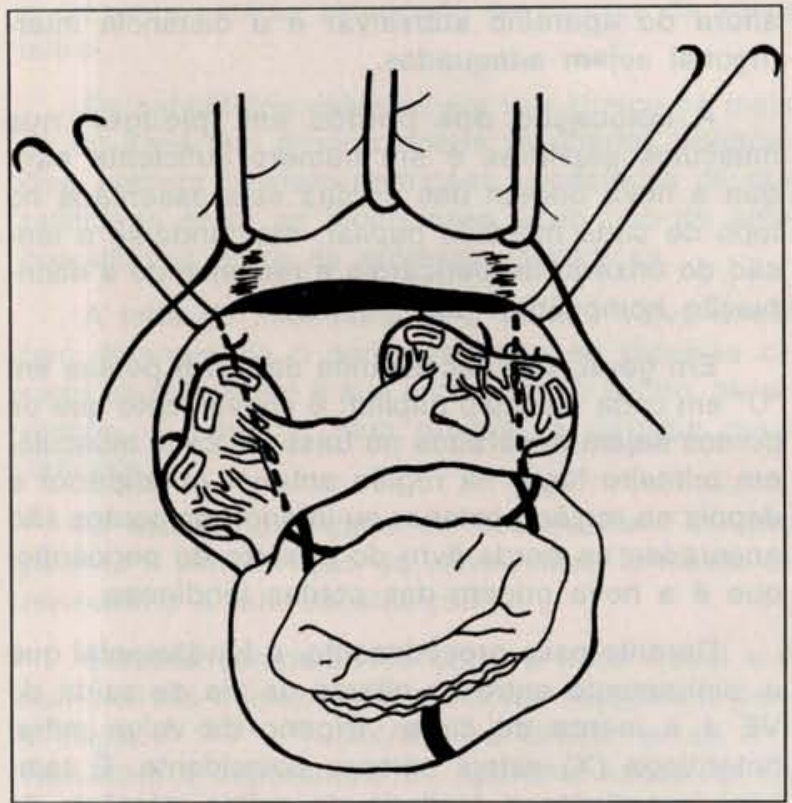

Fig. 3 - Fixação do enxerto ao músculo papilar.

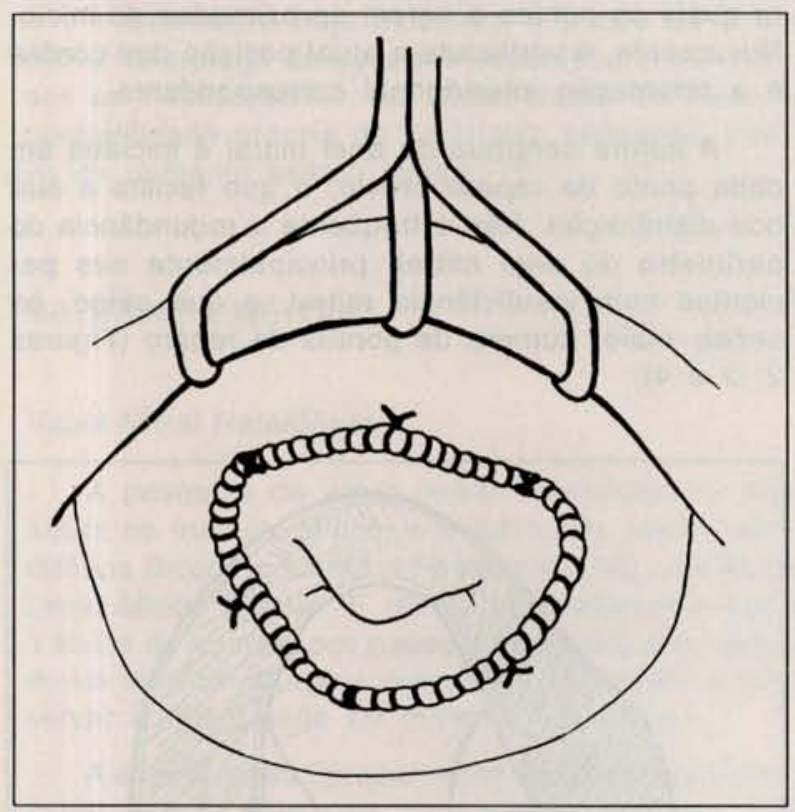

Fig. 4 - Sutura anular.

Após as manobras para a determinação da suficiência da valva, as bordas da atriotomia esquerda são aproximadas de modo habitual.

Terminada a circulação extracorpórea, é feita a análise ecocardiográfica, que visa determinar a área valvar, a nórmalidade do substituto e a identificação do sincronismo do septo interventricular.

O seguimento da técnica mencionada tem con- tribuído para que os resultados sejam consistentes, proporcionando não só o bom funcionamento valvar, mas principalmente preservando a função do VE. O tempo de isquemia miocárdica variou de 50 $\min$ a $73 \mathrm{~min}$, reduzindo-se sensivelmente, no decorrer da experiência.

\section{Dados Clínicos}

De março de 1992 a março de 1993, 38 pacientes foram submetidos, nesta Instituição, a troca da valva mitral com o novo substituto valvar "stentless", denominado valva mitral heteróloga.

A idade variou de 14 anos a 60 anos, com média de 29 anos. O sexo predominante foi o feminino, com 26 (69\%) pacientes.

A etiologia foi reumática, em $33(87 \%)$ pacientes, a endocardites em fase aguda em $3(8 \%)$ e doença mixomatosa em $2(5 \%)$ pacientes.

O tipo de lesão mitral é assim representado: estenose em $12(31 \%)$ pacientes, insuficiência em $6(16 \%)$ e dupla lesão em $20(53 \%)$ pacientes.

A troca da valva mitral foi a primeira operação em $32(84 \%)$ pacientes e em $6(16 \%)$, a segunda operação.

A classificação funcional inclui 18 (47\%) pacientes em classe III e $20(53 \%)$ em classe IV da NYHA.

O seguimento variou de 1 mês a 12 meses (média, 6 meses) (Tabela 1).

\section{RESULTADOS}

Todos os 38 pacientes estão vivos e assumindo suas funções anteriores. A média de internação foi de 9 dias.

A única complicação ocorreu na primeira paciente, por falha no protocolo. Tratava-se de uma insuficiência mitral de grande repercussão hemodinâmica; a escolha do substituto valvar foi inadequada; no pós-operatório, evoluiu com insuficiência mitral moderada persistente, determinando a substituição 2 semanas após a primeira operação. A paciente evoluiu satisfatoriamente e encontra-se em class funcional I, sendo portadora de uma bioprótese convencional.

Houve 1 caso de revisão de hemostasia com evolução satisfatória.

Todos os pacientes foram submetidos a exames clínico, hematológico e ecocardiográfico na alta hospitalar, e a seguimento trimestral. 
VRANDECIC, M. O.; GONTIJO FILHO, B.; FANTINI, F. A.; PAULA E SILVA, J. A.; BARBOSA, J. T.; GUTIERREZ, C.; BARBOSA, M. R.; OLIVEIRA, S. A.; MOREA, M. - Tranplante heterólogo de valva mitral. Nova alternativa cirúrgica: estudo clínico inicial. Rev. Bras. Cir. Cardiovasc., 8(2):83-90, 1993.

TABELA 1

VALVA MITRAL HETERÓLOGA

DADOS CLÍNICOS

$N=38$

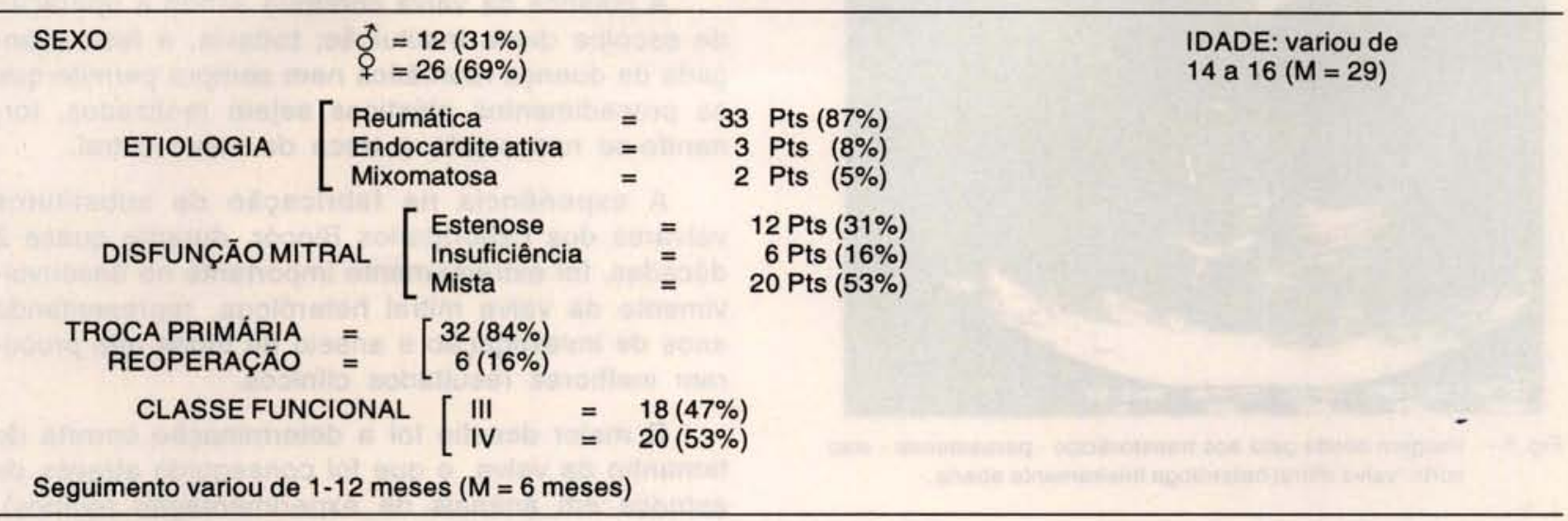

Houve melhora significativa na classe funcional; $30(79 \%)$ pacientes estão em classe funcional I e $7(18 \%)$ em classe funcional II. Não houve evidências de hemólise.

É importante ressaltar a boa cicatrização e a excelente aparência de valva observada na única paciente reoperada; a análise histológica mostrou tecido normal e sem evidências de microtrombose.

A análise ecocardiográfica foi realizada com aparelho ATL-ULTRA MARK 7 - colordoppler, usando-se a técnica convencional e, em 10 pacientes, por via transesofágica.

Foram realizados 5 exames de cateterismo cardíaco.

Os resultados da análise ecocardiográfica em 37 pacientes são extremamente gratificantes, tendo demonstrado total normalidade da valva mitral em
$27(73 \%)$ pacientes, $6(16 \%)$ pacientes apresentaram jatos finos a nível valvar e $4(11 \%)$ pacientes com insuficiência leve. Houve apenas 1 caso de insuficiência mitral moderada, que representa a única reoperação referente ao substituto valvar.

Foi observada diminuição do tamanho atrial e ventricular. $\mathrm{O}$ aspecto anatômico do novo complexo valvar é satisfatório, demonstrando mobilidade adequada de ambas as cúspides.

O gradiente transvalvar, pela ecocardiografia, foi em média de $5 \mathrm{mmHg}$; todavia, nos pacientes submetidos a cateterismo cardíaco, não houve gradiente transvalvar demonstrável. A área valvar média é de $2,3 \mathrm{~cm}^{2}$; a função ventricular tende a se normalizar e o septo interventricular preserva o movimento sincronico (Tabela 2).

Em nenhumn paciente foi observado aumento do diâmetro ventricular (Figuras 5 e 6).

TABELA 2

VALVAMITRAL HETERÓLOGA

DADOS HEMODINAMMICOS COM O USO DO DOPPLER VALORES MÉDIOS

$N=38$

\begin{tabular}{|c|c|c|c|c|}
\hline $\begin{array}{c}\text { ÁREA DE } \\
\text { SUPERFICIE } \\
\text { CORPÓREA }\end{array}$ & $\begin{array}{c}\text { DIÂMETRO DA } \\
\text { VÁLVULAMITRAL } \\
\text { STENTLESS }\end{array}$ & $\begin{array}{c}\text { GRADIENTE } \\
\text { (PICO) } \\
\text { MM HG }\end{array}$ & $\begin{array}{c}\text { PRESSURE HALF-TIME (P.H.T.) SEG } \\
\text { AREA VALVAR (CMR) }\end{array}$ & $\begin{array}{l}\text { GRAU DE } \\
\text { INSUFICIEENCIA }\end{array}$ \\
\hline $\begin{array}{c}1.3 \text { a } 1.7 \\
M^{2}\end{array}$ & 25 a 29 & $\begin{array}{c}5.1 \text { a } 14 \\
\text { Média }=5.6\end{array}$ & $\begin{array}{c}81.5 \text { a } 120 \text { P.H.T. }(M=48 \mathrm{seg}) \\
1.6 \text { a } 3.2 \mathrm{~cm}^{2}(M=2.5)\end{array}$ & $\begin{array}{lr}\text { SEM } & 27 \\
\text { TRIVAL } & 6 \\
\text { LEVE } & 4 \\
\text { MODERADA } 1^{*}\end{array}$ \\
\hline
\end{tabular}

- A única reoperação desta série. 
VRANDECIC, M. O.; GONTIJO FILHO, B.; FANTINI, F. A.; PAULA E SILVA, J. A.; BARBOSA, J. T.; GUTIERREZ, C.; BARBOSA, M. R.; OLIVEIRA, S. A.; MOREA, M. - Tranplante heterólogo de valva mitral. Nova alternativa cirúrgica: estudo clínico inicial. Rev. Bras. Cir. Cardiovasc., 8(2):83-90, 1993.

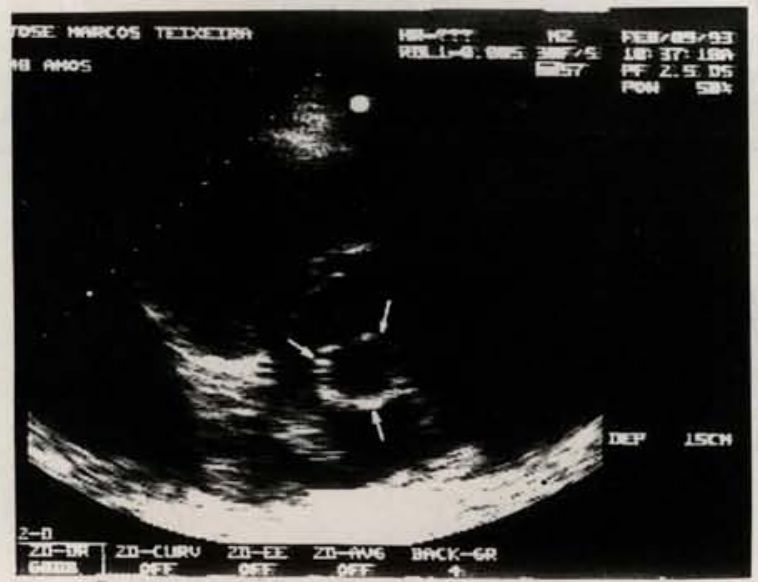

Fig. 5 - Imagem obtida pelo eco transtorácico - paraesternal - eixo curto: valva mitral heteróloga inteiramente aberta.

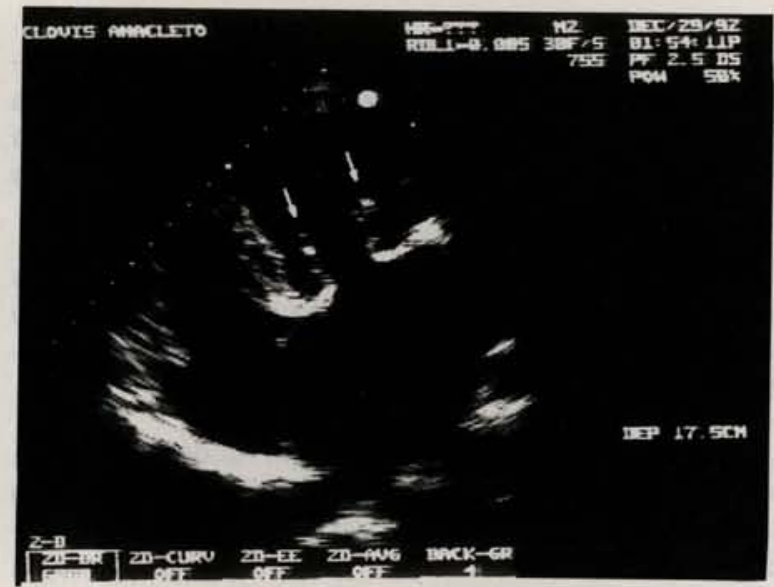

Fig. 6 - Imagem obtida pelo eco transtorácico - em corte apical 4 câmaras, demonstrando ampla abertura e ambos os folhetos da valva mitral heteróloga.

\section{COMENTÁRIOS}

A anatomia e a função do aparelho valvar mitral determinam a boa contratilidade do ventrículo esquerdo.

Os resultados clínicos da substituição da valva mitral utilizando-se o desenho aórtico são bem conhecidos ${ }^{21-23} \mathrm{e}$, certamente, podem ainda ser melhorados usando-se um desenho específico 20 .
Nos últimos anos, tem sido enfatizada a preservação, pelo menos parcial, do aparelho subvalvar, com objetivo de melhorar os resultados 12, 13, 17 .

A plástica da valva continua sendo a operação de escolha desta Instituição; todavia, a fase avançada da doença reumática nem sempre permite que os procedimentos plásticos sejam realizados, tornando-se necessária a troca da valva mitral.

A experiência na fabricação de substitutos valvares dos Laboratórios Biocór, durante quase 2 décadas, foi extremamente importante no desenvolvimento da valva mitral heteróloga, representando anos de investigação e anseio de todos que procuram melhores resultados clínicos.

O maior desafio foi a determinação correta do tamanho da valva, o que foi conseguido através de estudos em animais de experimentação (suínos), permitindo um protocolo confiável. A técnica cirúrgica é consistente, proporcionando resultados satisfatórios em todos os pacientes operados, nos quais houve adesão ao protocolo desenvolvido.

A única reoperação da valva mitral heteróloga proporcionou uma oportunidade de se observar a excelente cicatrização a nível papilar e o aspecto natural da valva.

A necessidade de um melhor substituto, assim como os excelentes resultados obtidos com o uso desse primeiro modelo mitral, tem aumentado o nosso nível de confiança.

Tanto o substituto, quanto a técnica cirúrgica, têm se mostrado inteiramente confiáveis.

Essa nova opção, que é a primeira valva mitral heteróloga, e a consistência de bons resultados da técnica de implante são, em realidade, da maior relevância na procura de um melhor substituto valvar mitral.

Os resultados in vitro e em animais de experimentação (carneiro) permitem prever a redução substancial do proceso degenerativo (comum a tecidos tratados pelo glutaraldeído).

Essa primeira valva mitral heteróloga, submetida ao novo tratamento biológico, que demonstrou ausência de calcificação e de reação tipo "corpo estranho", foi usada nos últimos 6 pacientes dessa série; espera-se, assim, maior durabilidade e meIhor qualidade de vida a esses pacientes portadores desse primeiro substituto valvar mitral heterólogo. 
VRANDECIC, M. O.; GONTIJO FILHO, B.; FANTINI, F. A.; PAULA E SILVA, J. A.; BARBOSA, J. T.; GUTIERREZ, C.; BARBOSA, M. R.; OLIVEIRA, S. A.; MOREA, M. - Tranplante heterólogo de valva mitral. Nova alternativa cirúrgica: estudo clínico inicial. Rev. Bras. Cir. Cardiovasc., 8(2):83-90, 1993.

RBCCV 44205-202

VRANDECIC, M. O.; GONTIJO FILHO, B.; FANTINI, F. A.; PAULA e SILVA, J. A.; BARBOSA, J. T.; GUTIERREZ, C.; BARBOSA, M. R.; OLIVEIRA, S. A.; MOREA, M. - Heterologous mitral valve transplant. New surgical technique: initial clinical trial. Rev. Bras. Cir. Cardiovasc., 8 (2):83-90, 1993.

ABSTRACT: Mitral valve replacement has been performed for the last 30 years using an aortic designed valve, to fulfil specific requirements of the left ventricle. The clinical results obtained by such devices have been generally favorable, although specific restrictions are obvious because of their design. The knowledge and experience acquired by Biocor Laboratories in the last two decades, in production of biological heart valve substitutes, contributed positively to the research, development and manufacture of the heterologous mitral valve substitute. This stentless heterologous mitral valve was implanted in 38 patients, without hospital mortality. Their mean age was 29 years. Female gender predominated $(69 \%)$. The most common mitral dysfunction was the double mitral valve lesion (53\%). Eighteen (47\%) patients were in functional class III and $20(53 \%)$ in class IV of the NYHA. There was one valve related complication (our first patient), due to disproportion of patients, large annulus and the incorrectly size chosen. This complication led us to the strict adherence of our protocol, which is based upon animal experimentation. The satisfactory operatory and clinical results, throughout this 12 months of follow-up, confirm that the stentless heterologous mitral valve is the natural mitral substitute, when considering mitral valve replacement. This first natural mitral valve substitute, tanned with a non-aldehyde tissue treatment, proved to avoid calcification and to produce no foreign reaction, hence it may be the best choice in order to obtain better quality of life and the desired valve durability. Using both, the natural design mitral valve and the non-aldehyde treatment, the last 6 patients of this series received this devicxe and is certainly hoped that, due to the more natural model and the noncalcificant and inhert tissue, patients own cells will be responsible to greatly delay tissue degeneration, providing longterm durability.

DESCRIPTORS: heart valves, mitral, surgery; heart valves, surgery.

AGRADECIMENTO: Nossos mais sinceros agradecimentos ao Corpo Clínico, Depto. de Estatística e Publicação desta Instituição, pelo desempenho na elaboração deste manuscrito, em especial às Srtas. Cristina Gomes Gurgel e Maria Aparecida Pereira.

\section{REFERÊNCIAS BIBLIOGRÁFICAS}

1 ADEBO, O. A. \& ROSS, K. J. - Surgical treatment of ruptured mitral valve chordae: a comparison between valve replacement and valve repair. Thorac. Cardiovasc. Surg., 32: 139-142, 1984.

2 BAILEY, C. P. \& BOLTON, H. F. - Surgical treatment of aortic stenosis. J. Thorac. Cardiovasc. Surg., 31: 275-281, 1956.

3 BRUNTON, L. - Possibility of treating mitral stenosis by surgical methods. Lancet, 1: 352-547, 1902.

4 CARABELLO, B. A.; USHER, B. W.; HENDRIX, G. H.; ASSEY, M. E.; CRAWFORD, F. A.; LEAMAN, R. B. - Predictors of outcome in patients with aortic regurgatation and left ventricular dysfunction: a change in the measuring stick. J. Am. Coll. Cardiol., 10: 991-997, 1987.

5 Carabello, B. A.; William, h.; Gash, A. K. Hemodynamic predictors of outcome in patients undergoing valve replacement. Circulation, 74: 1309-1316, 1986.

6 CARPENTIER, A.; DELOCHE, A.; DAUPTAIN, J. - A new reconstructive operation for correction of mitral and tricuspid insufficiency. J. Thoracic. Cardiovasc. Surg., 61: 1-9, 1971.

7 DAVID, T. E. - Mitral valve replacement with preservation of chordae tendineae: rotionale and technical considerations. Ann. Thorac. Surg., 41: 680-682, 1982.

8 DAVID, T. E.; EDEN, D. E.; STRAUSS, H. D. - The importance of the mitral apparatus in left ventricular function after correction of mitral regurgitation. Circulation, 68 (Supl. 2): 76-82, 1983.

9 DAVID, T. E.; STRAUSS, A. D.; MESHER, E.; ANDERSON, M. J.; MACDONALD, I. L.; BUDA, A. J. - Is it important to preserve the chordae tendineae and papillary muscles during mitral valve replacement? Can. J. Surg., 24: 236-239, 1981.

10 DURAN, C. G. \& UBAGE, J. L. M. - Clinical and hemodynamic performance of a totally flexible prosthetic ring for atrioventricular valve reconstruction. Ann. Thorac. Surg., 22: 458-465, 1976.

11 GLOVER, R. P. \& DAVILA, J. C. - The treatment of mitral insufficiency by the purse. String technique: 
VRANDECIC, M. O.; GONTIJO FILHO, B.; FANTINI, F. A.; PAULA E SILVA, J. A.; BARBOSA, J. T.; GUTIERREZ, C.; BARBOSA, M. R.; OLIVEIRA, S. A.; MOREA, M. - Tranplante heterólogo de valva mitral. Nova alternativa cirúrgica: estudo clínico inicial. Rev. Bras. Cir. Cardiovasc., 8(2):83-90, 1993.

initial clinical application. J. Thorac. Surg., 33: 75$80,1957$.

GREGORI Jr., F.; TAKEDA, R. T.; SILVA, S. S.; FAÇANHA, L. A.; RIBEIRO, J. A.; AQUINO, W. F.; SHIGUERU, S.; GOIS, L. E.; SIQUEIRA, J. E.; KRELING, P. A.; GOULART, M. P.; FABIANO, M.; GRULAN, A. I.; MIGUITA, L. C.; CANESIN, O. - Sete anos de experiência com plastia de valva mitral. Arq. Bras. Cardiol., 47: 269-274, 1986.

13 ISOM, O. W.; DEMOBROW, J. M.; GLASSMAN, E.; PASTERNACK, B. S.; SACKLER, J. P.; SPENCER, F. C. - Factors influencing long term survival after isolated aortic valve replacement. Circulation, $\mathbf{5 0}$ (Supl. 2): 154-162, 1974.

14 OLIVEIRA, D. B. G.; DAWKINS, K. D.; KAY, P. H.; PANETH, M. - Chordal rupture: comparison between repair and replacement. Br. Heart J., 50: 318-324, 1983.

15 OURY, J. H.; PETERSON, K. L.; FOLKERTH, T. L.; DAILY, P. O. - Mitral valve replacement versus reconstruction: an analysis of indications and results of mitral valve procedures in a consecutive series of 80 patients. J. Thorac. Cardiovasc. Surg., 73: 256235, 1977.

ROSS, D. N. - Hitorical perspective of surgery on mitral valve. In: Duran, C. (ed.) Recent progress in mitral valve disease. New York, Butter Worths, 1984. p. 5-9.

17 RZPICH, J.; CARABELLO, B.; USHER, B.; KRATZ, J.;
BELL, A.; ZILE, M. A. - Mechanism by which ejection performance is preserved following mitral valve repair but not replacement for chronic mitral regur-gitation. Circulation, 84 (Supl. 2): 578, 1991. (Resumo).

18 SOUTTAR, H. S. - Surgical treatment of mitral stenosis. Br. Med. J., 2: 603-609, 1925.

19 TUFFIER, T. - Actual de la chirurgie intra-thoracique. International Congress of Medicine. (Transactions). London, 1914. Seção 7 (Surgery), Parte 2, p. 249.

20 VRANDECIC, M.; GONTIJO, B.; FANTINI, F. A.; GUTIERREZ, C.; PAULA E SILA, J. A.; BARBOSA, J. T.; ANDRADE, C. A. O. - Anatomically complete heterograft mitral valve substitute: surgical technique and immediate results. J. Heart Valve Dis., 1: 254 259, 1992.

21 VRANDECIC, M.; GONTIJO, B.; PAULA E SILVA, J. A. - Clinical results with the Biocor porcine bioprosthesis. J. Cardiovasc. Surg., 32: 807-813, 1991.

VRANDECIC, M.; GONTIJO, B.; PAULA E SILVA, J. A. - Clinical results with the use of the Biocor bioprosthesis: a multicentric study. In: D'ALESSANDRO, L. C. - Heart Surgery, 1989. p. 227-242.

23 VRANDECIC, M.; GONTIJO, B.; RABELO, S. - Clinical experience with a new generation of porcine bioprosthesis. In: BODNAR E. \& YACOUB M. (eds.) Biologic bioprosthetic valves: International Symposium $3^{2}$ (Procedimings). New York, York Medical Books, 1986. p. 559-665. 